\title{
Apuntando deseos,
}

pasiones y poderes:

registrar vínculos

para "levantar villa".

Los escribanos de San

Felipe de Aconcagua,

Chile, 1740-1837

Writing Down Desires, Passions and Powers: Recording Social Bonds to "Raise a City". Notaries of San Felipe de Aconcagua, Chile, I740-I837

Recibido: 13 de febrero del 2017

Aprobado: 18 de abril del 2017
MARÍA EUGENIA ALBORNOZ VÁSQUEZ

Revista Historia y Justicia, Chile maujialbornoz@gmail.com

AUDE ARGOUSE Universidad de Chile oddargo@gmail.com
La escritura pública construye vínculos sociales, como ocurre en San Felipe de Aconcagua, entre su fundación (1740) y el orden de los archivos que realiza un escribano en 1836. Más allá de registrar eventos importantes para la ciudad, la actividad de los escribanos, o de quienes aseguran sus registros, muestra que en este periodo la cultura y la práctica jurídicas se transmiten cotidianamente e importan a todos. Igualmente, que los autores y custodios de las escrituras y de los archivos notariales intervienen en el ámbito judicial, político y cultural de la jurisdicción, desde 
sus trayectorias, afectos y experiencias. Esta humanización de la figura del escribano diluye los estereotipos asociados a su rol y enriquece la comprensión del proceso de "levantar villa".

Palabras claves: historia social, historia cultural, historia urbana, escribanos, registros notariales, San Felipe de Aconcagua, Chile, siglo XVIII, siglo XIX.

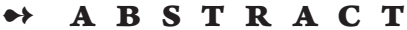

Public writings build social links, as it occurred in San Felipe de Aconcagua, between the village's foundation (1740) and the classification of the notarial archives by a notary in 1836 . More than recording important events for the history of the city, the notaries' activity, or of anyone who would carry out the public writings, show how legal culture and practices mattered and were transmitted day-to-day.
It highlights that clients and persons in charge of public writings and their conservation, take part in the judicial, political and cultural spheres of the jurisdiction, from their own careers, affects and experiences. Thus, bringing back the notary to its own humanity wanes the stereotypes and helps understanding the process of "levantar la villa".

Keywords: social history, cultural history, urban history, notaries, notaries records, San Felipe de Aconcagua, Chile, xviIth century, xIxth century.

\section{Introducción ${ }^{1}$}

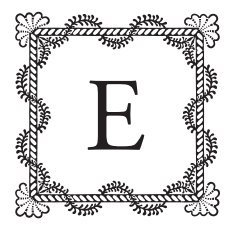

ste artículo interroga la escritura pública notarial en la construcción de los vínculos de San Felipe - entre su fundación y la organización de sus archivos notariales, casi cien años después-, considerando el registro de la escritura pública como lugar de compromisos donde se expresan las pasiones y los contornos del poder. 
Las Ordenanzas de 1703 buscaban instalar poblaciones españolas (Lorenzo). San Felipe fue fundada en 1740 por impulso del gobernador Manso de Velasco, para que los habitantes de los cinco valles del corregimiento de Aconcagua -Curimón, Santa Rosa, Aconcagua, Putaendo y Llay Llay - se agruparan y abandonaran los transitorios ranchos que, para las autoridades, significaban pobreza y malos hábitos (Lacoste). Los 34 terratenientes convocados compartieron [...] la urgente necesidad que padecían de que se fundase una población villa o ciudad donde se enseñase la doctrina cristiana a la juventud a leer y escribir y le instruyesen en todas letras estando en sociabilidad política a la consecución de tan importante bien común a todos los vecinos moradores y transeúntes. (ANH, CG, vol. 937, ff. 2 v.-3)

La sociabilidad era "el tratamiento, y correspondencia de unas personas con otras" (Diccionario). La sociabilidad política de la vida urbana es un concepto clave de la historiografía de los Estado-naciones en América Latina (González; Herzog, Defining), "ha sido asimilado a las formas con las cuales las élites latinoamericanas formaron sociedades de intercambio de conocimientos, y de relaciones políticas, económicas, sociales y culturales" (Guarín-Martínez 26), y empieza con la contribución voluntaria para levantar los edificios principales (iglesia, cabildo, cárcel). La Instrucción para Pobladores de 1740 mandaba abrir un registro en el archivo de la villa donde constaran esas contribuciones, disponibles para acreditar méritos para quien lo solicitara (Salvat).

La villa, situada a 90 kilómetros de Santiago — capital del reino y sede de la Real Audiencia-, tuvo una posición estratégica: en la ruta de Valparaíso a Buenos Aires, pasando por Mendoza (que perteneció al reino de Chile hasta I776), al otro lado de la cordillera de los Andes, por donde también circulaba el contrabando. La "necesidad de hacer villa" implicaba dotarse de medios para controlar ese fructuoso comercio entre el Atlántico y el Pacífico, más ventajoso que la ruta del estrecho de Magallanes (Cavieres; Tobar). Pero ¿esa sociabilidad política proclamada en la fundación atañe solo a un pequeño grupo deseoso de controlar esos intercambios? ¿O bien obliga a todos los habitantes de la villa?

Es intrigante esa "urgente necesidad que padecían" los habitantes de los valles. Por otro lado, el necesario entendimiento de los "vecinos, moradores y

2015 (dirigido por María Eugenia Albornoz Vásquez). También se apoya en las reflexiones surgidas de los proyectos Fondecyt/Conicyt Postdoctoral n. 3130658 (2012-2015) e Iniciación n. ${ }^{\circ}$ III50817 (2015-2018), dirigidos por Aude Argouse. 
transeúntes de San Felipe” remite a la responsabilidad de cada quien. ¿Cómo se construye una localidad, en el juego de las instituciones mayores y en la cotidianidad de las disputas y conflictos? Más allá de la decisión política de "hacer vida urbana”, ¿cómo vivieron los actores este movimiento, sabiendo que sus trayectorias se conectaban con lugares distantes o intereses divergentes? ¿Qué relaciones mantuvieron los registros de escritura pública jurídica no judicial con los expedientes judiciales?

La crítica moral de los registros, cuya huella también está en las cláusulas, adquiere importancia en el contexto del mandato de "necesario entendimiento", presente en el acto fundacional de I740. Los registros de escritura pública muestran cómo actúan y se mueven los habitantes de la villa. Pero la política de la villa, que va más allá de la actividad del cuerpo capitular (Albornoz, "El Cabildo") —inaugurado solo en $\mathbf{7 4 4 4}$, por designación del superintendente de la villa-, ¿ocurre también a través del juego alternado y controlado, de las prácticas contractuales y testamentarias? (Argouse, Je le dis pour mémoire). ¿Qué rol desempeñan los otros actos notariales (inventarios, poderes, garantías) en el diseño y en la organización de las prácticas de intercambio?

La mayoría de los volúmenes y protocolos de San Felipe estudiados aquí poseen índices, que analizamos como guías del acceso al escribano. La búsqueda de la escritura pública es una práctica extendida entre los habitantes de la villa: el aprendizaje y difusión de la cultura jurídica se realiza mediante la práctica notarial, independientemente de la existencia de un escribano titular. El trabajo de Francisco Villegas, autor hacia 1836 de los índices mencionados, parece fundamental para la evaluación historiográfica de los datos notariales, que se describirá en la primera parte de este texto. En la segunda parte, una lectura microscópica de diversos actos notariales develará la importancia y el lugar de los afectos como vectores de vínculos sociales en los tres tiempos (pasado, presente, futuro) en la villa de San Felipe y su jurisdicción.

En esta sociedad jerarquizada con forma de villa, donde se cruzan comerciantes y terratenientes, hijos naturales y legítimos, y que "obliga a llevarse bien" (Albornoz, "La temporalidad”), ¿qué validez tiene el mandato de entenderse "como hermanos", escrito en los actos testamentarios, y que resuena con aquel de la fundación de la villa? Percibimos el riesgo permanente - presente en las conciencias y en los actos notariales - del desgarro del tejido social, sometido a fuertes tensiones entre individuos (Loraux). ¿La familia y su consignación por escrito ¿protegen de las disputas? Pese a la mala reputación historiográfica de los escribanos y de su supuesta promiscuidad con los jueces locales — de quienes también son 
secretarios en la práctica—, justamente porque aparece como lugar posible para la interpretación y la manipulación, la escritura pública facilita el enunciado de los desafíos de la memoria, judicial y jurídica, necesarias, más bien fundamentales, para el entendimiento colectivo (Burns; Herzog, Mediación; Mendoza; Mijares).

\section{Los índices como indicios}

\section{Los hombres al servicio de la escritura pública}

El fondo Notarios de San Felipe, según su catálogo, se compone de iı 8 volúmenes que reúnen las escrituras públicas desarrolladas entre I658 y I896. Consultamos los índices de 3I de ellos para el periodo I740-I837, según una aproximación de conjunto, intuitiva, para valorizar la historia de la escritura pública en la villa y jurisdicción de Aconcagua a través de quienes fueron sus responsables. Los volúmenes refieren a: I) protocolos notariales, 2) escrituras hechas ante jueces de campo y 3) escrituras públicas sin más precisión. La mayoría alberga escrituras protocolizadas, resultado del desempeño de escribanos identificados, y un tercio no proviene de un solo escribano, sino de "jueces de campo".

Mediante la escritura pública se instaló el hábito de acudir a diferentes personas en caso de ausencia del escribano, con el fin de, por una parte, asegurar una suerte de continuidad de la escritura pública ya iniciada, y que debía dialogar con aquellas producidas en otros lugares; y, por otra, de inscribir, conseguir un lugar para las propias inquietudes — experimentadas por cada habitante de la villa y su jurisdicción-, en la escritura pública de la colectividad.

Entre 1696 y 1739 la escritura pública se desempeñó en los valles del corregimiento (volúmenes 2 a 6). En la década de I670, desde Santiago, se crearon varias escribanías en las provincias del reino. Según el expediente para optar al cargo de escribano de Aconcagua, en Santiago, entre mayo de 1675 y enero de I676 se pregonó en seis ocasiones la oferta del oficio de escribano público para el corregimiento de Curimón y Aconcagua (ANH, RA, vol. 2104, pieza IO). La escritura pública del partido Aconcagua, cuando se identificaba a un especialista en particular, fue asumida por escribanos que no tenían la confirmación 
del título de escribano, como Juan González o Gaspar de Castro. Francisco Javier Henríquez fue el primer escribano de la villa y compró su oficio por 300 pesos el 28 de enero de I74I (ANH, CG, vol. 62I, ff. I65-I69). Según el padrón de I744, también fue poblador fundador de la villa; en 1745 describe su casa como [...] un solar que tengo yo el presente escribano todo tapiado y barbado y en lo interior su fábrica de teja cocina y despensa allí mismo y materiales para proseguir trabajando, calle de San Felipe y el costado del norte mirándolo al sur. (ANH, CG, vol. 937, f. I44 v.)

En los legajos de escrituras ante jueces de campo aparecen otros individuos: corregidor, subteniente de justicia, teniente de corregidor, juez de campo, alcalde de provincia, subdelegado, que ocasionalmente confeccionan escrituras, según la urgencia del caso y siempre, según ellos mismos apuntan, "a falta de escribano". A inicios del siglo xviII, Juan del Canto, Antonio de Castro, Bernardo de Zúńiga, Francisco de Palacios, por ejemplo, registran y firman actos notariales sin precisar si tienen vínculo con el oficio escribanil (ANH, NSF, vol. 3).

Junto a esas autoridades territoriales y capitulares, los hombres de iglesia generaban registros útiles a las escrituras públicas, incluidos los tenientes de cura - como Antonio de Alfaro, en I74I (ANH, NSF, vol. 8) - y aseguraban la puesta por escrito de los actos. Es más, la ausencia de escribano o teniente de corregidor no impedía que se otorgaran testamentos. Así, María de Viveros precisa que su marido falleció sin hacer su testamento "ni ante el escribano ni el teniente de este valle" (ANH, NSF, vol. 7, f. 2I, I742-I753). Ella y el hijo del difunto convencieron al maestre de campo, Pedro de Lecaros, en el sector de Santa Rosa, en abril de 1742 , de pedir al escribano Henríquez que protocolizara esa declaración de muerte sin haber testado "en el registro del presente escribano". Bartolomé Espinoza, franciscano, narró los últimos momentos del moribundo: "viendo la gravedad de su achaque y la distancia que había a lo del escribano o teniente corregidor para que le otorgase su testamento [le pregunté] si tenía hecha memoria o dado poder a que respondió que no". Consiguió dos testigos y preguntó a quién designaba como heredero, y a quién daría poder para confeccionar su testamento, y así designó a su esposa y a su hijo. Pero hubo casos en que esa ausencia no se suplió: el 26 de abril de 1744 Catalina de Toro explica que su hijo murió sin alcanzar a hacer su testamento, "por no haberse hallado pronto escribano ni juez" (ANH, NSF, vol. 7, f. 74).

Aun así, existe una relativa homogeneidad de las escrituras públicas. El examen del volumen 22 esboza tendencias generales, aunque algunas de sus 
características son especiales: es el único que refiere a un año, I803; está atribuido a Bernardo Marcoleta y contiene 93 instrumentos: 48 tratan de ventas de terrenos, y de ellos, un tercio (i6) concierne a mujeres o a parejas (matrimonios); se cuentan diez testamentos (seis femeninos) y diez poderes. Cuando se emplea papel sellado, es siempre el de sello tercero, y muchas veces resellado: por ejemplo, los del bienio I794-I795 fueron retimbrados con el sello del año I803 y los del bienio I790-I79I, revalidados manualmente con la frase "Valga para el reinado de Su Majestad el rey Don Carlos IV”. El aumento del precio del papel sellado, decretado por el rey en julio de I798, se aplicó en Chile desde I799: se duplicó el precio "para consolidar la deuda nacional ocasionada por los crecidos e indispensables gastos de la guerra” (ANH, CG, vol. 747, ff. IIO-III). El único auto del volumen hecho en papel sellado segundo — fechado en 1739 (sic) con un valor de seis reales, es resellado para I802-1803, a un valor, ahora, de doce reales - corresponde a un acto confeccionado en Santiago, ante el escribano Juan de Álamos, y es un poder para vender un terreno "en la villa de Aconcagua”.

Marcoleta, subdelegado, firma los actos notariales desde I803, presentándose como aparece en una petición de partición de bienes de Juana Espinoza, por un terreno que parece interesarle también a él (ANH, CG, vol. 747, f. 74 v.); en seguida, el subdelegado es nombrado "juez arbitrador" de la partición y procede a la tasación de bienes y de las tierras ( $\mathrm{ANH}, C G$, vol. 747, f. 9I). Los instrumentos siguientes demuestran que se concretaron las ventas y poderes correspondientes. Anacleto del Canto, alcalde ordinario en I802, se desempeńó como secretario de Marcoleta, quien fue también auxiliado por Fermín de Torres durante 1803 .

Desde 1799 la escritura pública de la villa, relativa a los residentes de la traza urbana, fue retomada por los subdelegados y los alcaldes ordinarios. En I809, al mismo tiempo que José Gregorio Fontecilla, escribano de San Felipe, certificaba actos como la renuncia del alguacil Juan José Olivares (por enfermedad) en favor de Anacleto del Canto (ANH, NSF, vol. 27, f. I60 v.), un escrito de don Juan Fernández, juez diputado, muestra que conocía los procedimientos:

Certifico cuanto haya lugar en derecho como, hallándome extendiendo este testamento a don José Castro, según aparece de las disposiciones anteriores y de estar el testador en su acuerdo natural para verificarlo según lo manifestaba, en cuyo acto le sobrevino un insulto, hasta rendir la vida por lo que quedó sin su debido cumplimiento. (ANH, NSF, vol. 27, f. 266) 
Desde I8I3 los oficiales encargados de la escritura pública fueron nuevamente escribanos: Juan Lorenzo Urra, José del Carmen Almanche, Juan Silva y Francisco de Villegas. Los actos escribaniles oficiales comportan sellos y rúbricas que solo pueden crear y emplear los escribanos confirmados en sus cargos: algunos de ellos se ofrecen en las páginas que siguen. Sus nombres y periodos se apuntan en la tabla I.

TA BLA I
\begin{tabular}{|l|c|c|} 
Escribanos de San Felipe confirmados en sus cargos (I706-I828) \\
\hline Nombre del escribano & $\begin{array}{c}\text { Volúmenes en que } \\
\text { aparece su firma }\end{array}$ & $\begin{array}{c}\text { Inicio y término } \\
\text { de su actividad }\end{array}$ \\
\hline Juan González & 3,4 y 5 & I706-I72I \\
\hline Gaspar de Castro & 5 y 6 & I730-I739 \\
\hline Francisco Henríquez & 7 y 8 & I742-I754 \\
\hline Carlos José Morales & 9 a I9 & I754-I800 \\
\hline José Gregorio Fontecilla & $23,25,27$ y 28 & I804-I8II \\
\hline Juan Silva & 30 y 34 & I 82 I-I 828 \\
\hline
\end{tabular}

Fuente: elaboración propia a partir de ANH, NSF.

Uno de los escribanos confirmados, Carlos José de Morales, ejerció la titularidad del cargo durante 46 años y dejó bastante información sobre su vida y su oficio. Morales confeccionó un primer testamento en $\mathrm{I} 787$ (ANH, NSF, vol. I4, f. 29I). Estuvo casado dos veces: su primer matrimonio, al parecer feliz, fue con Juana de Rojas. Luego de enviudar, se casó, en mayo de 1783, con María Josefa Jofré, en Santiago. Pero ella no lo siguió hasta San Felipe —decisión que él lamentó nombrando su ingratitud—, justo cuando su salud se deterioró: Morales estuvo enfermo largo tiempo, y por esa razón se ausentaba. En numerosos registros, su firma, al final de un acto jurídico redactado sin ningún trazo vacilante, atestigua una mano temblorosa. Ello indica la presencia, en el entorno del escribano titular, de escribientes encargados de producir y reproducir los actos notariales, que el titular del cargo validaba luego con su propia escritura. 


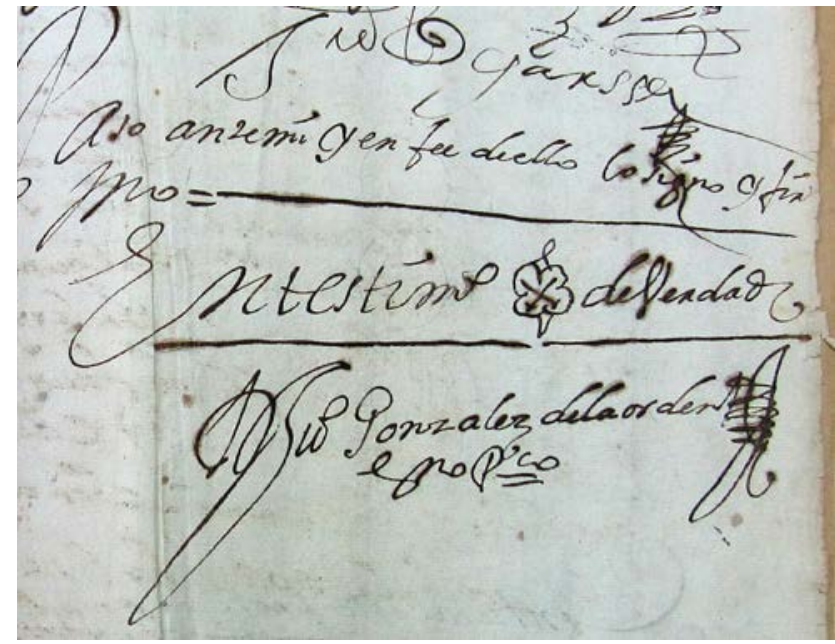

$\leadsto$ FIGURA I

Rúbrica y sello del escribano Juan González

Fuente: ANH, NSF, vol. O3, f. $17 \mathrm{I}^{2}$.

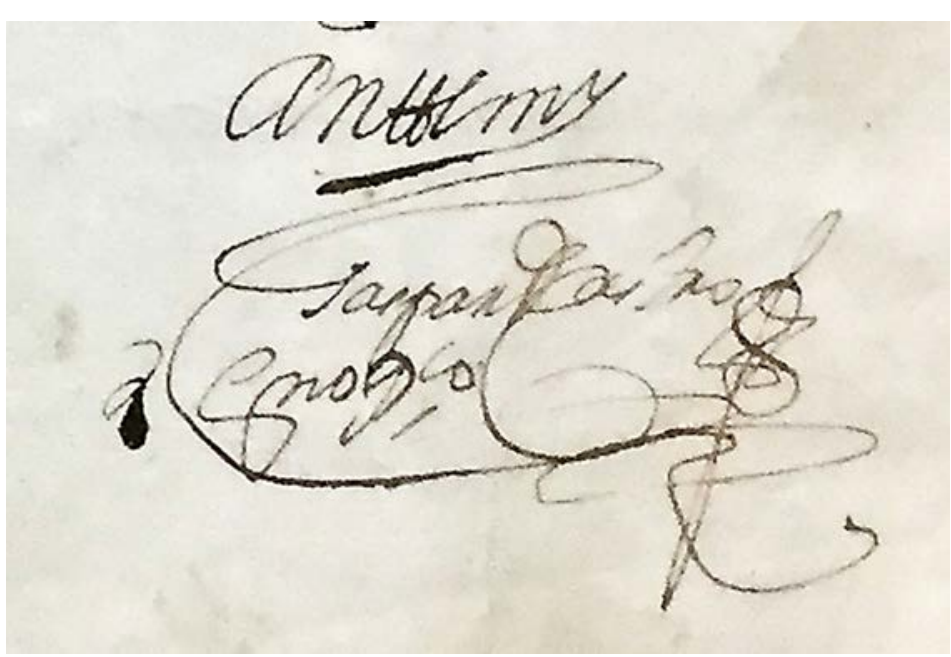

$\rightarrow$ FIGURA 2

Rúbrica del escribano Gaspar Castro

Fuente: ANH, NSF, vol. 06, f. 4I.

2 Todas las imágenes provienen del Archivo Nacional Histórico de Chile, Fondo Notarios de San Felipe (NSF) y Fondo Capitanía General (CG). Fotógrafa: Aude Argouse. 


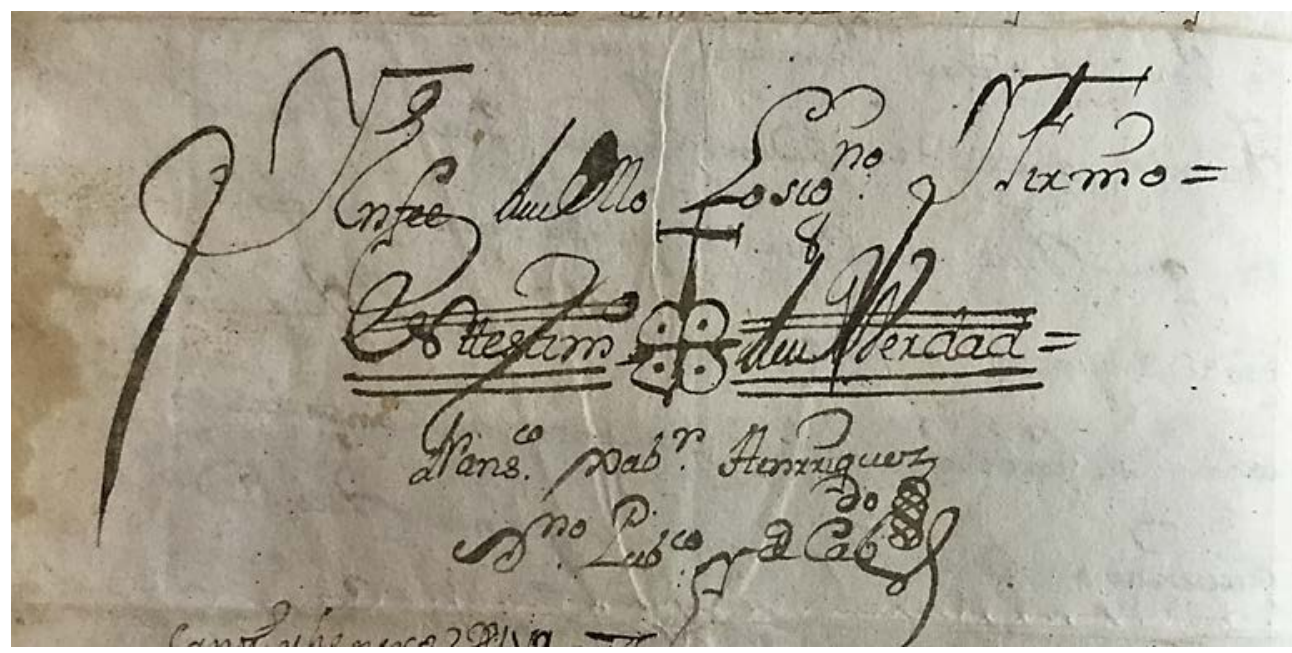

$\rightarrow$ FIGURA 3

Sello del escribano Francisco Javier Henríquez

Fuente: ANH, CG, vol. 937, f. I22 v.

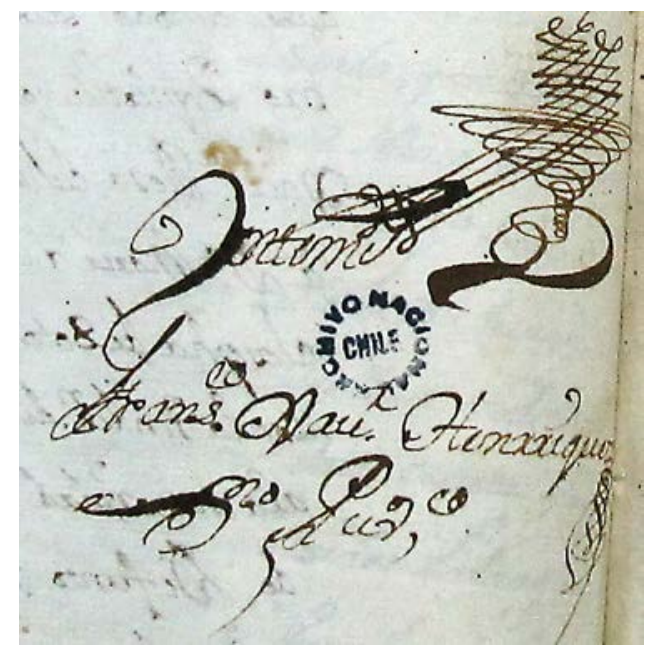

$\leftrightarrow$ FIGURA 4

Rúbrica del escribano Francisco Javier Henríquez Fuente: ANH, NSF, vol. o7, f. 55 v. 


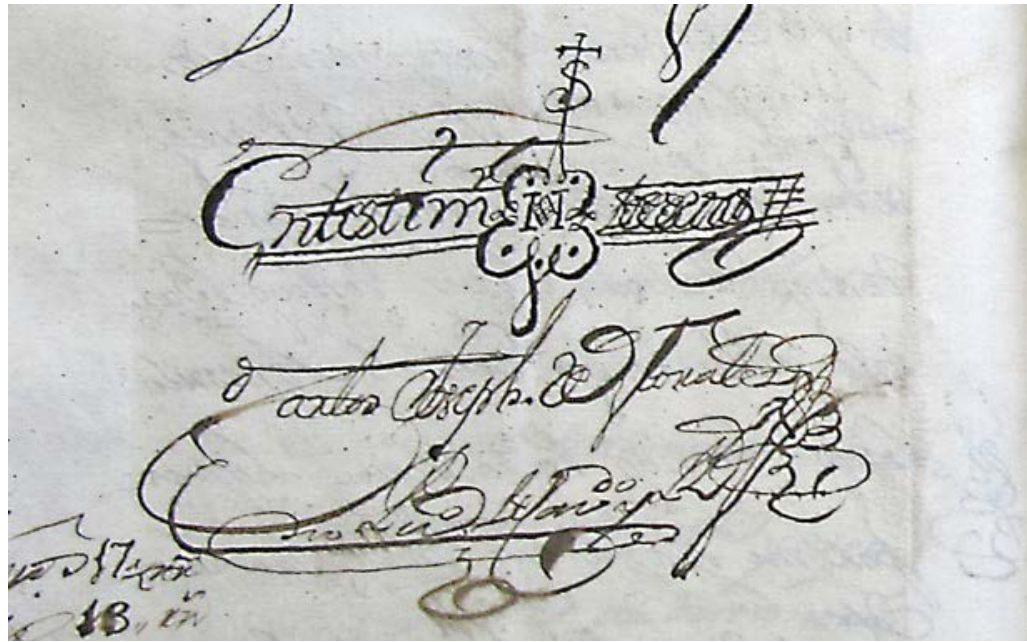

$\leftrightarrow$ FIGURA 5

Rúbrica y sello del escribano Carlos José Morales Fuente: ANH, NSF, vol. I9, f. 76.

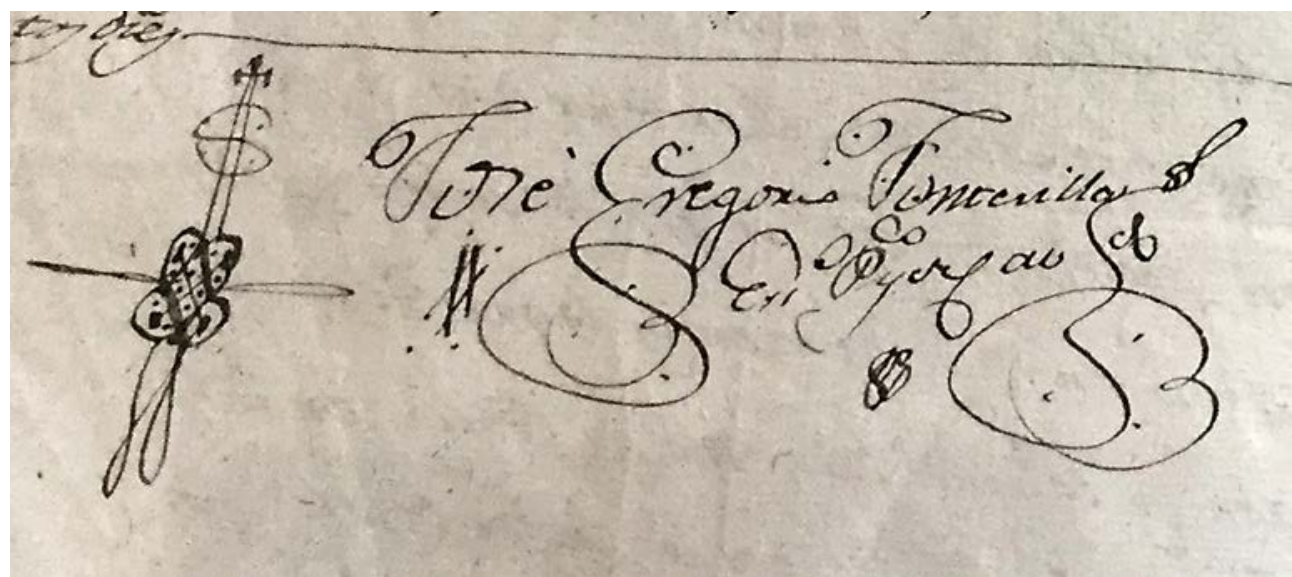

$\rightarrow$ FIGURA 6

Rúbrica y sello del escribano José Gregorio Fontecilla Fuente: ANH, CG, vol. 577, f. 283 v. 


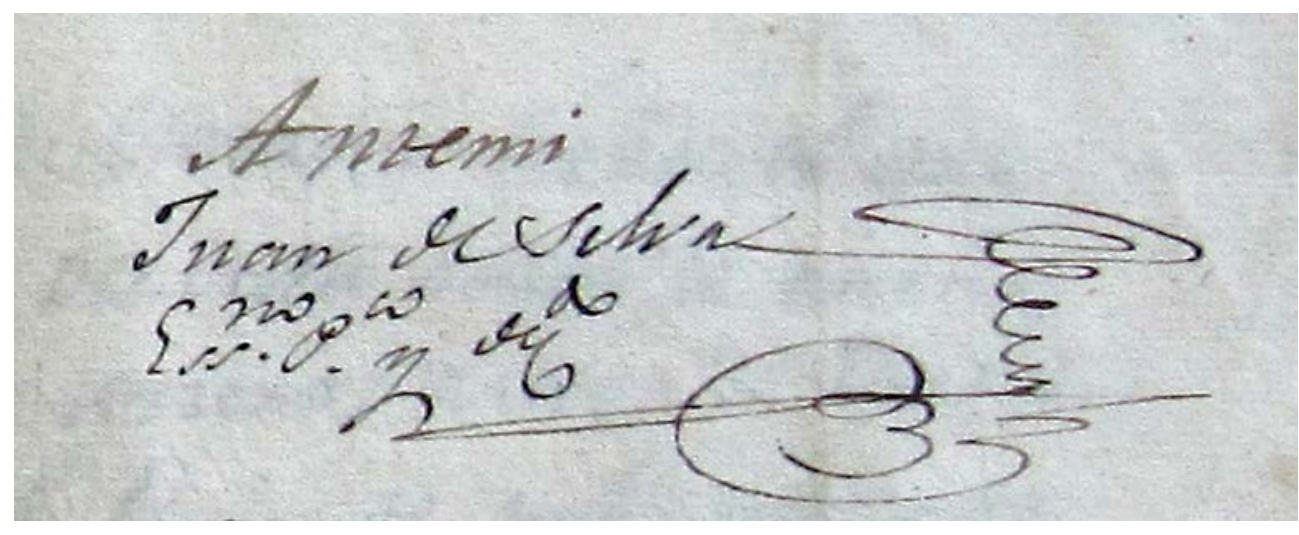

$\rightarrow$ FIGURA 7

Rúbrica del escribano Juan Silva

Fuente: ANH, NSF, vol. 34, f. 835

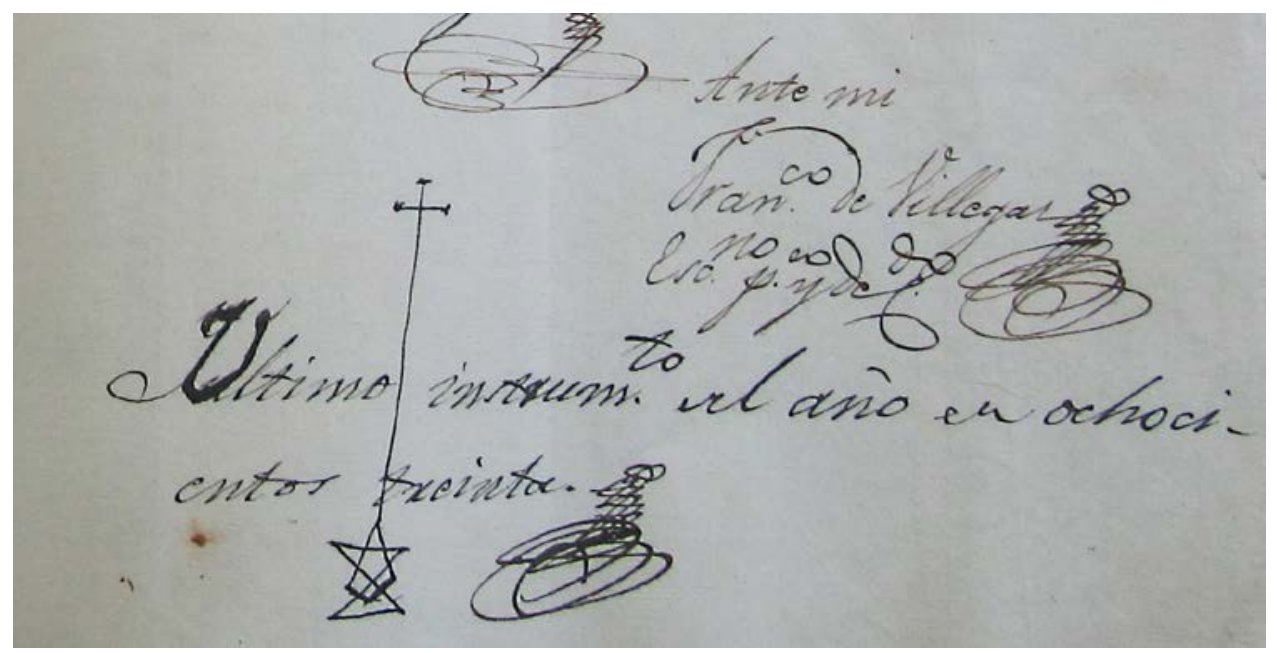

$\rightarrow$ FIGURA 8

Rúbrica y sello del escribano Francisco de Villegas

Fuente: ANH, NSF, vol. 35, f. 627. 
Morales decía que era natural de Santiago y que, en San Felipe, ante el corregidor Domingo de Salamanca, compró una casa que perteneció a don Gaspar de Arcaya, y antes, a la familia Del Canto, una de las primeras pobladoras de la villa. Morales adquirió una casa de una habitación, "en que al presente [I787] vivo con su techo muy maltratado y un rancho está existente de la misma suerte, todo lo cual refaccioné”. Le hizo mejoras y construyó una pared de tapia para separar su terreno de la casa vecina. Entre sus bienes, Morales indica:

[...] el oficio que sirvo de escribano público y de cabildo de esta villa de que me pertenecen o pertenecerán [sus bienes] a mis herederos los dos tercios de su valor rematado cuenta por no hallarse Pedro Ignacio y Alejo José de Morales mis hijos en quienes lo tengo.

Las cláusulas de su testamento dicen que la muerte de su primera esposa le afectó, tanto más cuando, un mes después de enviudar, la violenta crecida del río Mapocho de Santiago, de I783, se llevó la casa de sus suegros. Todo lo perturbó hasta el punto de "olvidar" confeccionar el testamento de su esposa:

[...] que habiendo fallecido dońa Juana Rojas mi mujer bajo la disposición de poder para testar que me otorgó ante el maestre de campo don José Antonio de Echevarría alcalde ordinario [...] como con el pesar de su muerte se me empapelase el dicho poder e inmediatamente sucediese en la ciudad de Santiago la grande avenida del río que se experimentó el día I7 de junio del ańo pasado de 83, con la cual se arruinó en el todo el sitio y casa que queda por muerte de los padres de la dicha mi mujer en que tenía parte como los demás sus hermanos con estos motivos me descuidé hasta lo presente y no he otorgado el testamento de la susodicha de cuya omisión por asi en él alguna manera les fuese perjudicial pido perdón a mis hijos. (ANH, NSF, vol. I4, f. 296 v., énfasis propio)

Morales confecciona el testamento de su esposa en octubre de 1787 , ante el subdelegado Fernando Polanco (ANH, NSF, vol. I5, f. II3 v.). En su propio testamento él se esfuerza por recordar dónde están los papeles o lo que contienen aquellos que se han perdido. Trata de mostrarse exhaustivo y pide ser perdonado por sus olvidos y errores. Confía en los registros, a los que remite con frecuencia, para encontrar allí la información necesaria. Pese a que su salud en I787 parece frágil, sobrevive aún catorce años más. Un segundo testamento, redactado en virtud de poder en I8oI, informa que Morales murió el 2I de septiembre de ese año aquejado de esa "grave enfermedad". El día anterior llamó 
a su hija, doña Rosa de Morales, al alcalde y a tres testigos para hacer su testamento "verbalmente", ya que no podía escribir. En su carta al juez, trámite que validaba el testamento verbal, Rosa cuenta que su padre había mandado "a suplicar a[l alcalde y juez], le hiciese favor de visitarle inmediatamente [...] a que contestó y políticamente, compareciendo con testigos para los fines que sobre el caso conveniesen". El alcalde precisa que fue llamado el i9 y el 20 de septiembre por el moribundo, que confirió poder a su hija, quien hizo registrar el testamento en noviembre de I80I. Rosa relató que su padre "era deudor de don Juan del Villar [...] con escasos bienes de fortuna”; y con respecto a su casa dijo que estaba "en la traza de esta villa cuadra y media de la plaza para la cańada del sur, cuyo sitio se halla edificado plantado custodiado de tapias y un majuelo de viña en su centro sin pensión de censo ni empeño alguno" (ANH, NSF, vol. 20, ff. 196-198). Morales dice ahora que de su primer matrimonio nacieron veintiún hijos,

[...] inclusos los abortos y maltardos (sic), y que de los que se acuerda la otorgante por ser de los menores son fray Tomás, don Alejo, don Ignacio, don Pedro Ignacio, don Antonio, doña María Rosa, doña Ignacia y doña Josefa Morales por haber muerto todos los restantes pequeños y que a todos los cuatro únicos que quedaban don Pedro Ignacio, la otorgante doña María Rosa, doña Ignacia y doña Josefa Morales.

De su segunda esposa, calificada de ingrata en el primer testamento y con quien no tuvo hijos, se dice: "no trajo bienes algunos al matrimonio pues para casarse con el citado mi padre este la vistió y dio una regular decencia por ser enteramente pobre y destituida" (ANH, NSF, vol. 20, ff. 199 v.-200).

También informa la hija del escribano sobre el estado general del archivo de su padre. Ese dato nos permite situar entre i8or y la década de I830 la destrucción parcial de la documentación notarial local (si no, ¿cómo explicar que los legajos de Morales, entre otros, hayan sido reconstituidos, sobre todo sus índices y tapas, por el escribano Villegas en I836?) La cláusula del testamento de Morales establece para ellos un buen estado de conservación:

[...] el archivo público y de este cabildo en el que se encontrarán todos los documentos y papeles de su cargo y que los legajos de escrituras, poderes, cesiones, donaciones, transacciones, traspasos y demás documentos de esta naturaleza actuados por dicho mi finado padre quedaban encuadernados y guarnecidos en pergamino foliados con abecedario y carátula los que aparecieran: y los demás papeles de causas civiles, 
criminales y legajos de ellas apeladas; y los que encontró en la oficina de su cargo cuando remató la escribanía u oficio público de este partido y que el dicho oficio lo tenía confirmado por el soberano según en varias ocasiones mucho antes de su fallecimiento le oyó decir. (ANH, NSF, vol. 20, ff. 200-200 v.)

Por otra parte, Rosa reitera el estatus de su padre como escribano confirmado por el rey, lo que interpretamos como la necesidad de dejar constancia de que él no era un escribano sin título. Durante los siglos XVI al XVIII, la práctica era el verdadero viático de los escribanos para atestiguar la capacidad de ser "hombre sabedor de escribir", como dicen las Siete Partidas. Pero esta cláusula subraya que la confirmación importa para la memoria de un hombre (y de sus herederos), pese a haberse desempeñado como escribano por más de cuatro décadas, muy cuidadoso de su archivo y de su oficio, tal como subrayan sus dos testamentos.

La escritura pública sobrepasa a sus servidores titulares, incluso cuando viven y aseguran el oficio, y ello, en dos dimensiones. Por un lado, los volúmenes correspondientes al periodo anterior a esta investigación muestran que, en el partido de Aconcagua, la consolidación de la escribanía fue progresiva y que pudo haber allí una transmisión familiar del "saber hacer" del oficio. Gaspar Castro, escribano de Aconcagua entre 1730 y I739, invita a indagar sobre la reproducción de la actividad escribanil en el seno del hogar: un posible pariente, Martín de Castro, firma en su ausencia (ANH, NSF, vol. 6, f. 57). El testamento de Morales hecho por su hija Rosa en I8or sugiere que las mujeres que rodeaban a los escribanos (hijas, esposas) pudieron aprender el oficio, sin estar autorizadas a ejercer el cargo:

[...] [su cama] me la dejaba a mí la otorgante y una escribanía [...] en recompensa de mi servicio personal por haberle asistido con el cuidado y atención posible en todo el tiempo de su dilatada enfermedad como es notorio y público haber estado muchos años baldado y casi impedido. (ANH, NSF, vol. 20, f. 200 v.)

Por otro lado, el acceso, la producción y la gestión de la escritura pública no constituyen un saber exclusivo del escribano público de la villa. En el paraje rural de Reculemu, en la vecina jurisdicción de Quillota, el juez diputado don José Vergara pone por escrito un acuerdo de venta, en diciembre de I789: aunque parece seguir la oralidad del intercambio, el documento, apuntado 
en papel con sello tercero del bienio de I737-1738 (sic), contiene información suficiente para validar el acuerdo e inscribirlo en el libro de registro público de Aconcagua (anH, NSF, vol. I6, f. 73). En las jurisdicciones se conocían las formas escriturarias y había personas sabedoras del oficio, por haberlo visto o asistido.

Dado que la mayoría de los autos tienen que ver con transmisión patrimonial, personajes como el citado subdelegado Marcoleta de inicios del siglo XIx, al apropiarse de la escritura pública, refuerzan su poder efectivo sobre los intercambios locales: hacen tasaciones de bienes, actúan como jueces árbitros en particiones, autentifican testamentos y ventas. Si bien el actuar de los jueces de campo, alcaldes ordinarios o jueces subalternos se concentra en solucionar conflictos y asegurar la positiva sociabilidad local, el dominio de la escritura pública y el manejo del archivo notarial de la villa les procura un control amplio sobre el actuar de los habitantes y las posibilidades de gestionar sus propios intereses. En ese contexto, importa saber que, no obstante ese control, Morales se considera pobre, y menciona como únicos bienes muebles algunas pailas, tinajas y cańones de alambique: es poco amenazante, sin ambición de hacer carrera política en San Felipe (o quizá, sin posibilidad de competir).

Ese no fue el caso del citado Fontecilla, acusado en I804 de haberse comportado mal con los jueces. El alcalde José Ignacio de Herrera dice:

[...] me he visto [en] diversas ocasiones en la consternación de reprender lo que el escribano de este cabildo diariamente ha estado cometiendo y hablando libertinamente contra los jueces, expresando que son unos hijos de puta y que ha de hacer por donde los pongan en un Valdivia, que mi compañero Blas Osorio es un burro, que se lo ha dicho en su propia casa, con otras expresiones denigrantes a presencia de varios que a la verdad y con justa razón se han escandalizado. (ANH, $R A$, vol. 568, f. 9)

También se reprocha a Fontecilla la confección de escritos útiles para los litigantes: lo acusan de empujar quimeras y discordias, y de facilitar defensa y representación para prisioneros. Es decir, de enfrentar al cuerpo de autoridades con jurisdicción judicial. Herrera llegó a la conclusión, luego de varias tentativas fracasadas de hacer razonar al escribano, "de que es imposible conseguir por medios ningunos sujetar el inmenso mar de su fatal lengua especialmente en algunas horas del día" (ANH, $R A$, vol. 568, f. 9 v., énfasis propio), y acentúa su constatación solicitando a Marcoleta para que, como juez, "exting[a] el maligno cáncer que se le espera a este infeliz pueblo teniendo en poder de 
semejante hombre un archivo en donde están depositados los intereses de los habitantes en él" (ANH, RA, vol. 568, f. IO, énfasis propio). Este convoca a don José Santos Hernández, oficial de la escribanía de la villa vecina Santa Rosa de los Andes, para que declare qué sabe sobre el comportamiento de Fontecilla. Hernández dice:

[...] que con motivo de haberlo llevado el escribano don José Gregorio Fontecilla por amanuense al que declara en el tiempo que lo estuvo, notó que dicho escribano hablaba descaradamente, y sin el menor rebozo contra todas las justicias de aquel lugar, y principalmente contra el señor subdelegado don Bernardo Marcoleta, expresando que era un hombre que no sabía su obligación y que a las partes les cobraba exorbitantes derechos por las diligencias que actuaba y que ahora que él estaba de escribano no había de robar tanto como robaba. (ANH, $R A$, vol. 568 , f. I4)

Al parecer, Fontecilla acostumbraba a denunciar a los jueces. Hernández confirma las acusaciones de Herrera y dibuja, en contrapunto, el perfil del escribano modelo: obediente, que copia los instrumentos tomando como ejemplo los archivos que están a su disposición, sin interponerse en las prorrogativas de los jueces, poniendo todo de su parte "para que caminase con buen éxito en su oficio de escribano". Fontecilla no se conformaba y acusaba abiertamente a los jueces de la provincia: "que eran unos ladrones y buenos para nada". Fue apresado, se fugó, pero fue atrapado e interrogado por Marcoleta. Aunque negó algunas de las acusaciones, como las injurias o su supuesto alcoholismo, reconoció haber dicho que los jueces eran ladrones porque "le robaban sus derechos" y haber ayudado a un preso que había denunciado al alcalde Torres, cercano a Marcoleta. Como también es interrogado sobre los archivos del oficio público y sobre las condiciones de trabajo del escribano, comprendemos que el conflicto está en el manejo de los registros públicos, disputado entre el escribano y los jueces (alcaldes capitulares, subdelegado del partido), y también, en la calificación del verdadero garante de los registros de escritura pública.

\section{La intervención de Francisco Villegas}

Los volúmenes y actuaciones de escribanos de San Felipe presentan huellas de una intervención a posteriori: Villegas es el autor de la mayoría de sus índices, 
ya que, según escribe él mismo, los protocolos que recibió como patrimonio de la escribanía carecían de tales instrumentos de clasificación. El volumen 2I del catálogo actual dice: "legajo I3 que contiene las escrituras y demás instrumentos públicos que se han organizado por hallarse sueltas y desmembrados correspondientes al año de 1802 ". Y el volumen 32 - que contiene, entre otros registros, vales para misas- es aún más preciso: “legajo 22 que contiene varias escrituras y toda clase de instrumentos públicos de diferentes fechas otorgados ante diversos jueces y escribanos que se encontraron sueltos interpolados entre los documentos pertenecientes al armario de cabildo después de concluido el inventario de escrituras".

Villegas confeccionó los índices para facilitar la consulta de los legajos "vigentes". La dimensión práctica de los índices sobresale y los títulos de los autos remiten a su clasificación: su trabajo es regular y sistemático. Pero no es raro encontrar la mención a la labor de archivo realizada por un escribano. Desde mediados del siglo XVIII, antes de las visitas realizadas a las escribanías por orden de la Corona, algunos escribanos de Santiago ordenaron sus archivos y levantaron inventarios. Las quejas entre colegas surgían cada cierto tiempo; pero lo que parecía un desorden en el ambiente escribanil era en realidad modos de gestión de los archivos que sustentaban el poder de su encargado (Argouse, "Prueba"). Se podían mantener la confusión, el retraso y el suspenso para molestar o entorpecer a algún competidor. Pero cuando el mercado del derecho comenzó a mostrarse competitivo, en particular durante el siglo xvinI, los escribanos debieron profesionalizar sus técnicas de clasificación y organización de sus archivos.

La sistematización de Villegas —en I836 y i837- surgió en un contexto relativamente similar: era escribano de la villa de Santa Rosa de los Andes cuando, en I828, la escribanía de San Felipe quedó vacante, y postuló apoyado en esa experiencia previa. Ese gusto por el orden no puede interpretarse solo como una afinidad singular, propia de alguien celoso de sus técnicas de clasificación. Al contrario, podría tener que ver con la aguda conciencia de Villegas sobre la importancia de su oficio en el mercado del derecho, que estaba en plena mutación. En 1858 algunas escribanías se transformaron en secretarías de tribunales y otras se mantuvieron como escribanías independientes (Thayer I: 5-7). El oficio, que desde hacía al menos un siglo se enfrentaba al surgimiento de los abogados, corría riesgo de muerte, a menos que ellos, los escribanos, demostraran que eran capaces de proponer un servicio irreprochable. 


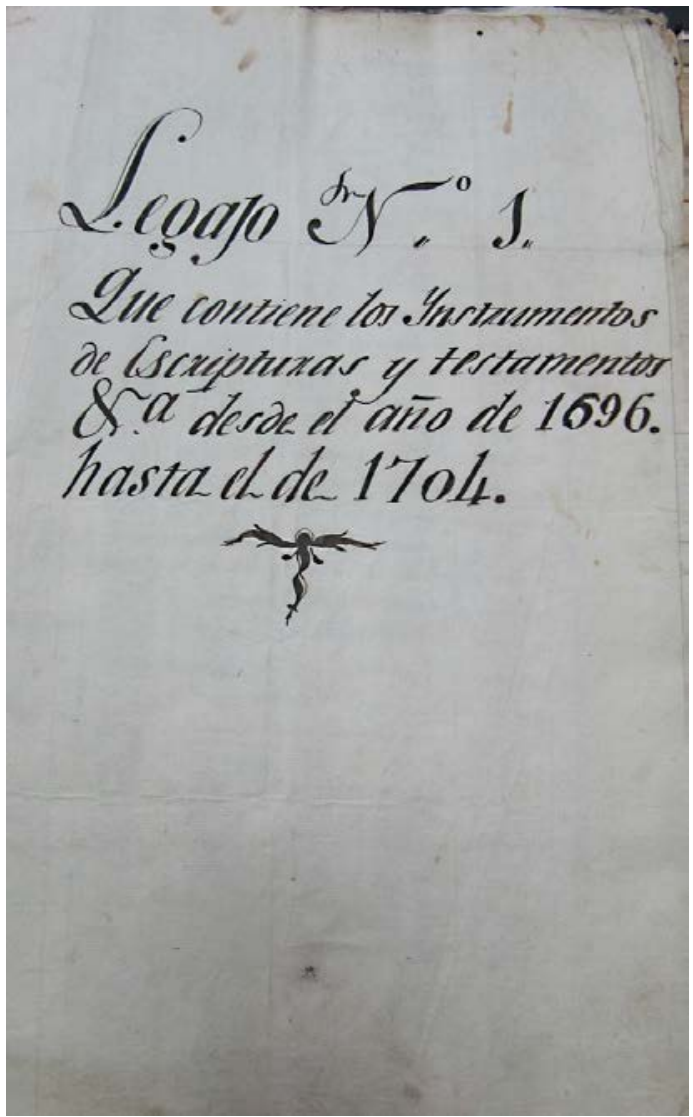

\section{$\rightarrow$ FIGURA 9}

Detalle de los índices de protocolos notariales confeccionados por Francisco Villegas en I836: "Portadilla del cuadernillo I"

Fuente: ANH, NSF, vol. 2, f. I.

Además, Villegas inició ese orden exhaustivo de los archivos de la escribanía de San Felipe en 1836, cuando terminaron los tribunales de conciliación, que funcionaron en todas las ciudades del país (ANH, RA, vol. 2631, pieza 5). Entre I824 y i836, por ley, un juez de conciliación debió enfrentar todos los conflictos menores y regularlos mediante comparendos amigables, para disminuir los litigios. Se trató de una medida propiciada por el Poder Judicial, en un intento doble: dirigir y administrar la resolución de conflictos de la población (Albornoz, "Cortar") y apropiarse de modalidades de acuerdo espontáneas de 
larga data, que usualmente requerían de los escribanos para concretarse. Tradicionalmente, en la cultura jurídica traspasada a los espacios hispanoamericanos católicos, ese rol era propio de los escribanos: el avenimiento, el convenio, la transacción y el compromiso eran modos de resolución de conflictos promovidos por hombres sabios - que podían o no ser jueces con titularidad de tales-, que se registraban ante los escribanos para evitar litigios ante la justicia ordinaria, descrita como brusca, lenta e ineficaz. El fracaso de la modalidad "conciliación obligatoria" chilena, que determinó su cierre, puede corresponder así a una reconquista del mercado de la conciliación, que opera en las oficinas de los escribanos. Las clasificaciones de los registros previos, que realiza Villegas, integrarían la puesta a disposición de la instancia notarial, herramienta que, además de desprenderse de la imperativa tutela judicial, debe batallar con la embestida de la abogacía profesional que desde la década de i830 está muy disponible en las ciudades chilenas para asesorar litigios. Al clasificar e indexar los registros, Villegas garantiza la eficacia de la escribanía en el seguimiento de los asuntos jurídicos, familiares y comerciales de todos los habitantes de la jurisdicción, a los que, como siempre, puede acceder cualquiera de manera independiente.

Este escribano, entonces, mediante sus usos y su orden, valoriza los archivos locales de escritura pública. Pero no es el único: ya antes Morales, entre 1754 y I800, concretó varias veces la misión de encontrar en sus registros "todos los actos que prueben” algo. Por ejemplo, el buen actuar del corregidor Domingo de Salamanca entre 1773 y 1777 (anH, JSFC, leg. 47, p. I5; Albornoz, Construyendo). Teniendo en cuenta ese requerimiento, que mezcla modernas funciones de notario y archivero con necesidades de crónica vital y memoria local, nos interrogamos sobre la "ausencia de los índices" que subraya Villegas a mediados de la década de I830: ¿realmente nunca existieron los índices e inventarios de la escribanía? De haberlos habido, como creemos, ¿qué sucedió con ellos? ¿Por qué hoy, en los mismos volúmenes del fondo actual, como el 5, se encuentran huellas de esos "órdenes" anteriores a Villegas? Como sea, su organización en índices de los contenidos de los volúmenes anteriores permite dibujar la fisonomía de los "datos notariales", es decir, del conjunto de registros disponibles para San Felipe hacia I836-I837. Y también asentar su marca en los cuadernos: Villegas contó el número de actos para cada volumen anterior a él y los confeccionados durante su trabajo profesional. 


\section{La fisonomía del dato notarial}

\section{Aprendizaje de la cultura jurídica}

Los autos de transmisión de bienes son mayoritarios: testamentos, inventarios, ventas. Las menciones de ventas de esclavos destacan, pero sobresalen las ventas de tierras o ventas de sitios. También hay obligaciones, donaciones, fianzas y poderes, pero en proporciones menores que para Santiago. Ello indica una dinámica "patrimonial" importante, que se mantiene disponible en los registros públicos, y que coincide con los expedientes del levantamiento de la villa en la década de 1740 - aunque los pobladores tienen prohibición de disponer de sus solares y chacras durante ocho años, y además se dictamina que los solares deben permanecer indivisos- (Lira; Salvat). La nómina de familias que tienen casas fabricadas en la villa muestra que varias tardaron en edificarlas; a fines de $\mathbf{7 4 5}$, el juez privativo de la villa de San Felipe, el oidor Juan de Balmaceda, multó a los retrasados y autorizó al corregidor a asignar solares no construidos a los nuevos pobladores que iban llegando: la propiedad urbana podía perderse debido al uso inadecuado (ANH, CG, vol. 937, f. I52, I745).

La práctica notarial se elabora desde los otorgantes (entre necesidades y voluntades) y se mezcla con la actividad administrativa de los oficiales públicos, en cuanto instrumentos de regulación de transacciones, acuerdos y contratos. Levantar villa es una promesa que el desarrollo de la escritura pública posibilita, contra las prácticas de los hacendados que buscan mantener sus privilegios. En I745, el juez privativo reclamó la aplicación estricta de las Instrucciones de I740 y la integración de los mercaderes y comerciantes a la villa, para que los intercambios ocurrieran en su seno; el cierre de las pulperías situadas a más de una legua, y, para las localizadas en la villa, su declaración de "francas y exentas de el real derecho de pulpería por tiempo de diez años"; la reunión de los oficios mecánicos (carpinteros, herreros, sastres, barberos y zapateros); y el respeto del corregidor a las ordenanzas: que concluya "la casa de cabildo, oficio de escribano y cárcel”, la construcción de puentes y la gestión del agua (ANH, $C G$, vol. 937 , f. I53, I745).

La recurrencia de apellidos muestra que algunos otorgantes se presentaban como "usuarios" frecuentes de la escritura pública. La amplitud de un 
"mercado" de tierras, la integración de extranjeros en la villa — que, por ser pobladores, tenían los mismos derechos que los españoles y locales (Lira; Salvat)— y la constitución del vecindario durante el periodo pueden ser cuestionadas con la adquisición de tierras y su transmisión a personas venidas de otros lugares. El testamento de don Pedro Pérez, natural de Ruyloba, en Santander, España, muestra que los afincados de San Felipe no eran solo los herederos de los primeros pobladores o vecinos de Santiago interesados en poseer tierras y obtener ganancias (anH, NSF, vol. I5, f. 70, 1787). Pérez se casó con una mujer de San Felipe, María Prudencia Silva, que aportó como dote el sitio y casas que fueron de sus padres, un esclavo, plata, ropa y joyas. Pérez, comerciante, poseía una tienda en la villa y declaró un patrimonio menor en mercadería local y europea. Precisó en su testamento, hecho en San Felipe, que sus sobrinos le informaron sobre los bienes raíces paternos en Ruyloba; dado que no tenía hijos, deseaba que su parte de esos bienes fuera cedida a su media hermana, María Pérez. La cláusula, encerrada en un registro escribanil de la villa de San Felipe, buscaba llegar hasta España (ANH, NSF, vol. I5, ff. 70-72).

Un poder hecho en 1758 por Cipriano Cabrera de los Olivos, alguacil mayor de San Felipe, a su cuñado Pedro Reyna, habitante de Santiago, muestra que la gestión de los casos conectados en la lejanía se practicaba mediante la competencia del escribano para redactar poderes que producirían efectos a distancia, lo que prueba la confianza en la eficacia de la escritura pública (Argouse, "Confianza"). Cabrera confió a Reyna, que viajaba hacia Lima, el cuidado de recuperar, ante el virrey, un dinero adeudado a su difunto padre, el general Cipriano de Cabrera, desde cuando servía en el corregimiento de Luya y Chillaos, en Perú. María de los Olivos, su viuda, y madre del otorgante, había requerido más de 4.000 pesos en las cajas reales de Potosí; ahora el hijo buscaba, desde San Felipe, cobrar esa deuda (ANH, NSF, vol. 9, ff. 206-206 v.).

Pareciera que, desde la década de I750, la actividad notarial de San Felipe logró posicionarse como referente en la materia para el partido: los registros son abundantes y los volúmenes, gruesos. La variedad de actos se intensifica y, a fines de siglo, refleja una cultura jurídica cada vez más refinada. Esto permite entender el papel de los escribanos en la administración de justicia y en la prevención, mediante el arreglo entre partes, de conflictos. ¿Atestiguan acaso una actividad que se diversifica con el tiempo? ¿Se trata de una competencia particular del escribano Morales? ¿O San Felipe permite el desarrollo de una administración a distancia, de la mano de la difusión de los saberes jurídicos, mediante un perfeccionamiento de su escritura pública? 
Con el tiempo, los registros públicos se convierten en lugares de denuncia, promesa y balance, cualquiera fuera su naturaleza o las circunstancias de su factura. Don Gregorio González informó que don José Camus, primer ejecutor testamentario, todavía no levantaba el inventario de bienes quedados a la muerte de doña Bartolina Zapata, su suegra, fallecida casi un año atrás (ANH, NSF, vol. I3, f. 28). Gregorio solicitó al corregidor para hacer valer su doble interés: como segundo ejecutor testamentario y como esposo de una hija de la difunta. Camus, hijo natural de Bartolina, residía en Santa Rosa de los Andes, al otro extremo de la jurisdicción. La dispersión de los herederos, así como su estatus de hijos naturales y legítimos, obstaculizaron la materialización del inventario. El corregidor lo realizó para terminar un conflicto latente sobre una sucesión mal arreglada. En junio de 1787 los herederos se presentaron ante el escribano Morales y el acto se anotó como "Compromiso de los herederos de don Juan de Herrera y doña Bartolina Zapata”:

[...] se les preparaba litis, y atendiendo a que los de esta naturaleza son por sí cuasi interminables a las costas y gastos inexcusables de ellos, a las rencillas y demás fatales consecuencias que traen consigo los litigios, por conformidad y paz han tratado de comprometer la dicha división y partición en el prudente juicio y arbitramiento del capitán de caballería don Juan del Villar vecino del dicho valle de Curimón [donde reside Camus] para lo cual se presentaron por escrito ante el [subdelegado, autoridad que desde 1786 reemplazó al corregidor]. (ANH, NSF, vol. I5, f. 64 v.)

El escribano generó una escritura de compromiso y se nombró a un "tasador partidor y juez árbitro arbitrador y amigable componedor”. Lugar de consenso, los registros escribaniles muestran múltiples razones para mermar un entendimiento frágil: frustraciones, manipulaciones y presiones también integran las acciones humanas, y los documentos conservan su memoria. La reflexión de Morales, apuntada en su testamento de 1787 , sobre la disposición y organización de sus propios archivos, indica que él manipuló y gestionó un conjunto de causas que concernían a los saberes jurídicos y judiciales de la jurisdicción:

[...] yo entré en posesión de este dicho oficio por el mes de octubre del año pasado de 1754 y obtuve los títulos de la confirmación de él y de notaría real por merced de Su Majestad (que Dios guarde) se dignó hacerme los cuales tengo entre mis papeles pero no tengo presentes sus fechas, todos los instrumentos públicos que ante mí se han otorgado se hallan en cinco protocolos encuadernados abecedados y forrados, que tengo formados 
de ellos, y de este presente año solo tengo un cuaderno completo y otro con algunas fojas escritas de dichos instrumentos, y en la actualidad me hallo arreglando, por legajos, los demás papeles de dicho oficio con separación de las causas civiles y criminales antiguas y modernas cuya diligencia concluiré si la divina voluntad fuera servida de concederme algún tiempo más de vida. (ANH, NSF, vol. I4, f. 295 v.)

Aunque el número de compromisos y transacciones es bajo a inicios de siglo, los inventarios, particiones y tasaciones de bienes demuestran una importante actividad de arbitraje. El aprendizaje del derecho y la multiplicación del saber jurídico no ocurren solo mediante las divisiones de bienes entre herederos. Pareciera que los jueces locales buscan cada vez menos la sentencia judicial. En I80s don José Antonio Echevarría denuncia a los herederos de don Cristóbal de Ahumada porque, omitiendo una convención que había designado a Marcoleta como árbitro, buscan llevar el caso ante la justicia. Después de denunciar que, al contrario, todo ocurrió dentro de la legalidad, dice:

[...] nadie puede reclamar contra él y caso de tener algún recurso con nuevos documentos debe instruirse ante los mismos jueces partidores, que lo son para todas las incidencias, siendo Vuestra Merced incompetente para conocer y máxime para ordenar la suspensión de lo obrado por quienes tuvieron facultad para ello. (ANH, NSF, vol. 25, f. 9)

\section{El examen de las conciencias locales}

En I809, ante la Real Audiencia, el procurador de San Felipe, Juan Nieto, acusa al subdelegado José Tocornal de haber hecho mal uso de los últimos ingresos públicos. La visita del fiscal Sánchez dice que el Cabildo "no meditó sus responsabilidades, de que no lo excusa esos vanos temores, si resultasen ciertos los hechos representados por su procurador" (ANH, CG, vol. 577, ff. I6-I8). El mandato de meditar las responsabilidades, destinado a un órgano colegiado, no es ajeno a las prácticas de reflexión y de exploración de la interioridad, que también ocurren desde la escritura pública. Así, cuando dicta su testamento, y después de sacar cuentas y enunciar posesiones, la ya citada Bartolina retoma un acuerdo que pactó con un yerno. Natural de Santiago y viuda de don Juan de Herrera, precisa: 
Me dieron mis padres la ropa y ajuar de mi persona regularmente decente; un par de zarcillos de oro con perlas grandes de los que se usaban en la antigüedad; seis platos y doce candeleros de plata; dos esclavos nombrados Matías negro y Gertrudis mulata; un escritorio todo dorado; una cajita mediana y treinta mulas nuevas y el dicho mi marido entró por vía de capital las tierras que hubo por herencia de don Juan de Herrera su padre que son las que poseo con las dichas mis hijas; una mesita ordinaria y un escaparate pequeño. (ANH, NSF, vol. I3, ff. 32-32 v., I78I)

Bartolina agrega que la esclava Gertrudis tuvo un hijo, Francisco, que también recibió de sus padres como dote, y que además poseía "dos esclavos mulatos nombrados Diego y María Dolores que me pertenecen en los bienes de dicho mi difunto marido por herencia del dicho don Juan José mi hijo". Esos cinco esclavos, dice, son los únicos bienes "en mi poder", y quiere que luego de su muerte se compartan entre sus dos hijas y sus nietos (hijos de Antonia, otra hija ya fallecida, que fue casada con Nicolás de Silva, y a quien ella dotó con "un molino de pan" y dos esclavas). Su tercera hija, Josefa Herrera, a quien ella no dotó con bienes raíces, estaba casada con Gregorio; ello explica el interés de este en denunciar el retraso de Camus. Bartolina, como muchas viudas de San Felipe, asumió la responsabilidad de dotar a las hijas, pagar y cobrar las deudas del marido, y administrar tierras, animales y bienes que les permitían vivir a todos.

El esfuerzo de memoria, desplegado por Bartolina y registrado en escritura pública, se convierte en un ejercicio reflexivo y meditado, cuando agrega que su marido había vendido un pedazo de tierras a Agustín Gallardo. El comprador había pagado un tercio del valor total, a cambio de un recibo que Herrera le dio; las tierras no habían sido entregadas porque el precio no había sido pagado íntegramente. Bartolina dejó que abusaran de ella por el tiempo y por la proximidad con el comprador: "como andando el tiempo casase Antonio Gallardo hijo del dicho Augustín con doña Bartolina Henríquez mi nieta, con esta relación me persuadió a que le diese recibo de los dichos cien pesos y que los había pagado su padre, lo que no me consta, y sin reflexión alguna le di el recibo de ellos" (ANH, NSF, vol. I3, f. 34 v.).

Bartolina tuvo varios hijos naturales después de enviudar, entre los cuales estaban Camus, su albacea, y doña María Zapata, que permaneció cerca de ella para servirle ("no he tenido otra persona que me acompañe y sirva no como hija sino como pudiera hacerlo una esclava”). Es posible que el padre de esos 
hijos fuera Gerónimo de Camus, uno de los primeros pobladores de la villa y acreedor de su marido. Una cláusula parece indicarlo:

[...] reflexionando sobre la dependencia que al tiempo de su fallecimiento debía don Juan de Herrera mi marido a don Gerónimo de Camus me acuerda que entre mis papeles tengo varios en que consta que el dicho don Gerónimo hizo cesión de este débito a don José, doña Luisa, doña María Mercedes y doña María mis hijos naturales, habidos después de la muerte del dicho mi marido, y para que el total de dicha dependencia se les compensase en tierras de las que dejó por sus bienes el expresado mi marido y para que los dichos mis hijos naturales estén en esta inteligencia y usen del derecho que les convenga en este ánimo lo declaro. (ANH, NSF, vol. I3, ff. 36-36 v.)

El testamento de Bartolina, como otros, ilustra el paralelo que existe entre: I) los registros de los asuntos corrientes, 2) los responsables de los gastos públicos, y 3) los protocolos notariales: abundan arreglos, reclamaciones, pagos, rectificaciones, responsabilidades asumidas. ¿Dónde poner la frontera entre deber moral de reflexión y deseo de dejar constancia de una frustración que abrirá una vía a la reparación? Si, por su lado, Bartolina declara no válido — pero ¿es eso jurídicamente posible? - el acuerdo pactado con su yerno, porque estima haber sido débil cuando lo realizó, lo que expresa el escribano Morales en su primer testamento proviene de la amargura y del lamento ante la ingratitud de su segunda esposa. Anciano, también se refiere a sus hijos, ausentes de la villa. Responsable de sus deudas, precisa que uno de sus acreedores es don Diego Vásquez, a quién todavía debe el dinero gastado treinta años atrás en la compra de su oficio de escribano:

[...] mando se leguen de mis bienes lo que yo no [he] ejecutado por la distancia en que se halla y no saber a quién poder entregar dicho dinero después del fallecimiento del maestre de campo don Diego de Armeda, a quien tenía encomendada su recepción, y no pude satisfacerle por varios atrasos que me ocurrieron. (ANH, NSF, vol. I4, f. 296, I787)

En la parte central del documento, el escribano traduce en lenguaje jurídico las voluntades de los otorgantes, que constituyen la "parte medular" de la escritura notarial (Mijares 85). Los actos notariales representan entonces más que una simple práctica dictada por el hábito: se trata de una tecnología intelectual (Gardey) que está al servicio de la comunidad. Porque si el escrito 
puede ser manipulado así, también tiene vocación para ser interpretado, como una partitura susceptible de marcar el tono de los intercambios futuros. La responsabilidad de quienes acuden al escribano es así reforzada. En 1784, Manuel Gallardo, del valle de Putaendo, se dirige al corregidor Polanco para proteger a los cuatro hijos de su propio hijo, que murió asesinado, y a quien tuvo con su esposa Rosa Muñoz. Esta última se casó de nuevo, pero veinticinco días después murió. A Gallardo le inquieta el cariz del testamento que dejó Rosa:

[...] hubo antes de su fallecimiento de otorgar no sé qué especie de testamento, memoria, o por mejor explicar un desatino en sustancia revestida de cierta ignorancia crasa ante su lugarteniente de dicho valle [de Putaendo] hallándose este enteramente desnudo de tal facultad, avocándose rectrac[tal]lmente en este caso la de el escribano público y real de esta villa, dejando por singular albacea y tenedor de bienes al segundo marido, que en cuya virtud se halla en actual posesión de los pocos que por su fin y muerte quedaron, así muebles como semovientes, sin otro recaudo alguno. (ANH, NSF, vol. I4, f. 57)

Gallardo agrega que sus nietos se encuentran "desamparados a expendias [sic] del padrastro con conocimiento pleno de no ser este sujeto idóneo por su desarreglada conducta, así para sustentarlos como para la conservación de dichos bienes". Como no hay defensor de menores en la jurisdicción, él los representa y pide que se proceda pronto al inventario de bienes. Indisponible, el corregidor comisiona a su lugarteniente. El inventario, hecho en la casa donde vivía Rosa, nombró objetos y mulas, lo que seńala una vida de arrieros. Así, Gallardo cuestiona el testamento de su nuera, levantado por un lugarteniente; pero, por orden del corregidor, debe aceptar que otro lugarteniente realice el inventario de los bienes que quedaron a su muerte.

La ausencia de formas adecuadas puede también ser un elemento que esgrimir contra una querellante, al mismo tiempo que permite revelar un miedo; ese sentimiento, puesto por escrito, permite comenzar un procedimiento, justificar una decisión, manchar una reputación. Su presencia en los registros judiciales y jurídicos prueba que los sentimientos son un motor de decisiones (Albornoz, Experiencia; Albornoz, Sentimientos). Así, en I805, María de los Santos, deudora de la sucesión de don Manuel de Luco, recibe los reproches de don Antonio González, representante de don José Antonio Luco, albacea de su medio hermano Manuel. González acusa a María: mediante la producción de escrituras ("tres papeles simples con el renombre de documentos") mostraba 
su malicia como litigante. González siembra la duda sobre su solidez ("dos aparentes certificados instruidos el primero por el alcalde de barrio y el segundo por el juez territorial, pues cada uno patenti[za]rán la notoria nulidad de que se revisten"), y dice su temor de que tales papeles pudieran producir efectos (ANH, NSF, vol. 26, ff. 59-60, énfasis propio). Afirma incluso que la calidad del fallecido comerciante era incompatible con una mentalidad de mal pagador:

[...] pero que en descargo de la cantidad que al presente se le cobra haya contribuido con la más mínima data, es falso. No es de creer que un hombre intrínsecamente versado en la carrera comerciable [sic], y de un ánimo generoso, y cristiano [...] [como] don Manuel Luco. (AHN, NSF, vol. 26, f. 6o)

Manuel de Luco había sido procurador de la villa y alcalde varias veces. La escritura pública asegura la permanencia de su memoria, pero la hace vulnerable. No sería extraño que la "fragmentación" del archivo notarial de San Felipe (evocada por Villegas en 1836) se explique por la agitada y revolucionaria década de i8io: los papeles de la escribanía pueden haber sido usados como cartuchos de pólvora... o confiscados para ocultar vínculos y datos inconvenientes.

\section{Conclusión}

La historiografía chilena otorga una connotación especial a la ciudad de San Felipe, según tres eventos inauditos: I) fundada en 1740 como villa, en I770, luego de gestiones colectivas, el rey le concedió el título de "ciudad" con el lema "Fuerte y feliz" y un escudo; en menos de medio siglo de vida, San Felipe mejoró su estatus urbano; 2) en I8I3, luego del sofoco, por parte de residentes sanfelipeños organizados, de la pseudorrebelión realista liderada por el errático comerciante José Antonio Eseiza (Betancourt), surgida en la vecina villa de Los Andes, recibió de San Martín y O’Higgins el título de Ciudad Heroica; 3) en I8I8, luego del triunfo patriota de Chacabuco, la dirigencia republicana reforzó esa calidad con la divisa "Siempre Heroica Ciudad". Por otra parte, también se subraya la "rivalidad eterna" entre San Felipe y Los Andes — fundada en I79Identro de la subdelegación de Aconcagua, que se zanjó (pero no se terminó) con la creación en 1804 de la subdelegación de Los Andes (Cubillos). Todos 
son hitos de distinción políticos y militares de la élite capitular, en su camino hacia el lustre y brillo.

Pero nada se dice en esos relatos de éxito — reproducidos en folletos turísticos, medios de comunicación y manuales escolares- sobre cómo se forjó cotidianamente la villa-ciudad en las relaciones sociales, cuyos aspectos no se reducen a la actividad económica ni a los comportamientos demográficos. Subrayamos la indispensable agencia de los escribanos, que vehiculan (conservan, enseñan, manejan) la cultura jurídica; ejecutan y transmiten prácticas escriturales, jurídicas y judiciales; y contribuyen fuertemente a "levantar la villa” porque conceden voz, palabra, registro, archivo y memoria, además de legitimidad, a sus habitantes. Los escribanos, incluidos los notarios eclesiásticos y los sotacuras, inscriben en el registro, que es tiempo proyectivo y tiempo fijo, lo que sucede con cada quien, individual y colectivamente.

Los historiadores conocemos lo que ha sido una ciudad mediante los objetos, muebles e inmuebles, que han perdurado y, sobre todo, a través de sus registros escritos. Los autores, gestores, conservadores y, en gran medida, constructores y manipuladores de estos registros fueron los escribanos. Con sus circunstancias, conocimiento, experiencia, relaciones, aciertos y yerros "levantan la ciudad de papel”, que aquí es manuscrita, y tiñen, con su mano y palabras, sus sentires y decisiones, el espacio urbano que ellos mismos están legitimando.

Tenemos una gran deuda, no solo respecto de San Felipe — que gracias a sus escribanos, y en particular a Carlos José de Morales y Francisco de Villegas, ofrece una invaluable masa de ordenados registros manuscritos sobre la vida y actividad de sus habitantes - sino respecto de la historia, la memoria y el patrimonio cultural de las villas-ciudades de Hispanoamérica. Los escribanos fueron agentes protagónicos en la vida jurídica, que dominan-; judicial, de la que participan, y en la vida política, social y cultural, que integran. Las caricaturas del escribano avaro, displicente o maniático no dan cuenta de la riqueza y complejidad que sus abundantes y diversos registros ofrecen, y que son, en incuestionable constatación, la base de lo que vivieron y dijeron, en masculino y en femenino, sus habitantes.

La invitación a desarrollar este cruce, que requiere el diálogo entre la historia social, cultural, judicial, política y notarial, queda abierta: ¿podremos soñar con el surgimiento de más historias locales, así elaboradas para las villas y ciudades y con el advenimiento de una consiguiente etapa de estudios comparados a partir de este enfoque? 


\section{$\infty$

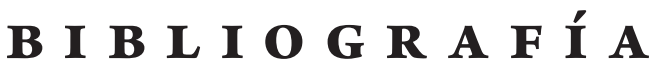

\section{F U E N T ES PRIMARIA S}

\section{A. Archivo}

Archivo Nacional Histórico, Santiago de Chile, Chile (ANH).

Capitanía General (CG) vols. 577, 621, 747, 937.

Judiciales San Felipe Civiles (JSFC) leg. 47.

Notarios San Felipe (NSF) vols. 3, 6, 7, 8, 9, I3, I 4, I5, I6, 20, 25, 26, 27.

Real Audiencia (RA) vols. 568, 2104, 2631.

\section{B. Impresos}

Diccionario de autoridades. Madrid: Real Academia de la Lengua Española, I739.

\section{F U E N T ES SECUNDARIAS}

Acevedo, Óscar y Sergio Fernández Larraín, editores. Fundación de ciudades en el reino de Chile. Santiago: Academia Chilena de la Historia, I986.

Albornoz Vásquez, María Eugenia. "El Cabildo de San Felipe: forjar la vida cívica en el valle de Aconcagua Chile, I750-I830". Ichan Tecolotl, I6 de junio del 2016. Web. Consultado el ro de diciembre del 2016.

---. Construyendo vínculos sociales: experiencias de pasión y de poder. San Felipe de Aconcagua, I740-I830. Santiago: Acto Editores, 2017.

---. “Cortar la causa, no admitir más escrito, obligar al perdón. Sentencias judiciales para administrar la paz quebrada por las injurias (Chile, I790-1873)”. Justicias, agentes y jurisdicciones. De la monarquía hispánica a los Estados nacionales (España y América, s. XVI-XIX), editado por Elisa Caselli. Madrid: Fondo de Cultura Económica, 2016, pp. I25-160.

---. Experiencias de conflicto: subjetividades, cuerpos y sentimientos en Chile, I739-I860. Santiago: Acto Editores, 2015.

---. "La temporalidad, las ausencias presentes y los motivos. Conflictos, justicias y género en una villa recién fundada: San Felipe, Chile, I747”. Nuevo Mundo 
Mundos Nuevos, 2012, DoI: 10.400o/nuevomundo.62745. Consultado el io de diciembre de 2016.

---, dir. Sentimientos y justicia. Coordenadas emotivas en la factura de experiencias judiciales. Chile, I650-1990. Santiago: Acto Editores, 2016.

Argouse, Aude. "Confianza y caridad en los protocolos notariales. ¿Emociones solemnes ante el escribano? Santiago de Chile, siglos XviI-Xvin". Sentimientos y justicia. Coordenadas emotivas en la factura de experiencias judiciales. Chile, I65oI990, editado por María Eugenia Albornoz Vásquez. Santiago: Acto Editores, 20I6, pp. 28-59.

---. "Je le dis pour mémoire". Testaments d'indiens, lieux d'une justice ordinaire. Cajamarca, Pérou, XVIIe siècle. París: Les Indes Savantes, 2016.

---. "Prueba, información y papeles. Hacia una historia del procedimiento ante escribano en Hispano América siglos XviI-Xviı". Revista Historia y Justicia, n. ${ }^{8}$, 20I7, pp. 97-I37.

Betancourt C., Francisco. "Redes y estrategias de un comerciante vasco. Ascenso y caída de José Antonio Ezeiza (I803-I8I3)”. Tesis de maestría, Universidad de Chile, 2012.

Burns, Katrhyn. Into the Archive: Writing and Power in Colonial Peru. Durham: Duke University Press, 2010.

Cavieres, Eduardo. "Formas de vida y estructuras demográficas de una sociedad colonial: San Felipe en la segunda mitad del siglo xviı". Cuadernos de Historia, n. ${ }^{\circ}$ 3, 1983, pp. 79-97.

Cubillos M., Adela. "Rivalidad entre las villas de San Felipe El Real y Santa Rosa de Los Andes". Aconcagua Cultural, vol. 2, n. ${ }^{\circ}$ I3, 2014, pp. 3-5.

Gardey, Delphine. Ecrire, calculer, classer. Comment une révolution de papier a transformé les sociétés contemporaines (I800-1940). París: Editions La Découverte, 2008.

González Bernaldo de Quirós, Pilar. "La sociabilidad y la historia política”. Conceptualizar lo que se ve. François-Xavier Guerra, historiador. Homenaje, editado por Erika Pani y Alicia Salmerón. Ciudad de México: Instituto Mora, 2004, pp. 4I9-46o.

Guarín-Martínez, Óscar. "La sociabilidad política: un juego de luces y sombras". Memoria y Sociedad, vol. I4, n. ${ }^{\circ}$ 29, 2010, pp. 25-36.

Herzog, Tamar. Defining Nations. Immigrants and Citizens in Early Modern Spain and Spanish America. New Haven: Yale University Press, 2003.

---. Mediación, archivos y ejercicio: los escribanos de Quito (siglo XVII). Frankfurt: Vittorio Klostermann, I996. 
Lacoste, Pablo, Estela Premat y Valentina Bulo. "Tierra cruda y formas de habitar el Reino de Chile”. Universum, vol. 29, n. ${ }^{\circ}$ I, 20I4, pp. 85-Io6, Dor: http://dx.doi. org/10.4067/So718-23762014000100005.

Lira Montt, Luis. "Privilegios concedidos a los pobladores de villas fundadas en el reino de Chile en el siglo xviı". Acevedo y Fernández, pp. 73-92.

Loraux, Nicole. La cité divisée. L'oubli dans la mémoire d’Athènes. París: Payot \& Rivages, I997.

Lorenzo Schiaffino, Santiago. Origen de las ciudades chilenas. Las fundaciones del siglo XVIII. Santiago: Andrés Bello, I983.

Mendoza García, Eva María. Los escribanos de Málaga en el reinado de Felipe IV (I62II665). Málaga: Servicio de Publicaciones, Centro de Ediciones de la Diputación de Málaga, 2007.

Mijares Ramírez, Ivonne. Escribanos y escrituras públicas en el siglo XVI. El caso de la ciudad de México. Ciudad de México: Universidad Nacional Autónoma de México, Instituto de Investigaciones Históricas, I997.

Salvat Monguillot, M. "En torno a la fundación de San Felipe E1 Real". Acevedo y Fernández, pp. Io5-II4.

Thayer Ojeda, Tomás. Guia para facilitar la consulta del Archivo de Escribanos de Santiago. 3 vols. Santiago: Imprenta Universitario, I9I4-I930.

Tobar, Leopoldo. "La sociedad del partido de Aconcagua, I700-I830". Estudios coloniales III, editado por Julio Retamal A. Santiago: Universidad Andrés Bello, 2004, pp. I57-215. 